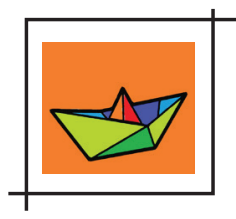

\title{
FLUSHING REMONSTRANCE: OS ANTECEDENTES DA LIBERDADE RELIGIOSA NA AMÉRICA DO NORTE
}

\author{
Ingrid Rachel Mendes Di Monaco* \\ Marcelo Martins Bueno**
}

\begin{abstract}
Resumo: A presente reflexão analisa as origens da liberdade religiosa na América do Norte. Partindo do movimento Flushing Remonstrance, ocorrido no século XVII, considerado um dos pioneiros em termos de protesto em defesa da tolerância e da liberdade religiosa, buscou-se identificar as principais caracteristicas do referido movimento que serviram de fundamentos para que a sociedade norte-americana fosse uma das primeiras nações a considerarem a questão em sua Constituição e em sua Carta de Direitos.
\end{abstract}

Palavras-chave: Religião. Liberdade. Tolerância. Protesto. América do Norte.

\section{INTRODUÇÃO}

0 presente artigo apresenta o resultado parcial da pesquisa bibliográfica sobre o movimento Flushing Remonstrance, que ganhou notoriedade por ser reconhecido como o primeiro protesto em defesa da liberdade religiosa em território norte-americano. Este protesto foi protagonizado por imigrantes europeus que viviam em Flushing, região colonizada, próximo à llha de Manhattan, em Nova York, quando o local ainda estava sob o domínio holandês, em 27 de dezembro de 1657. 0 evento documentado por historiadores configura importante eixo para a compreensão do pensamento e da cultura norte-americana a partir do fenômeno religioso. 0 princípio motivador do movimento, registrado na petição assinada por seus idealizadores, revela em termos claros que a religião ocupou um papel preponderante no estabelecimento de uma sociedade igualitária e livre, como resultado do fluxo migratório entre Europa e América do Norte, ocorrido no século XVII. 0 caráter fortemente inovador e original da sociedade neste período marcou decisivamente os séculos subsequentes, pois foram for-

\footnotetext{
* Mestre em Educação, Arte e História da Cultura pela Universidade Presbiteriana Mackenzie (UPM). E-mail: ingriddimonaco@ yahoo.com.br

** Mestre e doutor em Filosofia Política pela Pontificia Universidade Católica de São Paulo (PUC/SP). Professor Titular do Programa de Pós-Graduação em Educação, Arte e História da Cultura da Universidade Presbiteriana Mackenzie (UPM). E-mail: marcelo.bueno@mackenzie.br
} 
mulados princípios notadamente originais. Situado entre o Renascimento e o lluminismo, o século XVII foi responsável pelo florescimento das ciências, que deram impulsos essenciais à religião, à economia, à política, à sociedade e, sobretudo, às questões da liberdade, que ganharam novas interpretações.

A temática religiosa estava presente na vida dos imigrantes e não estava pacificada, como a história descreve. 0 direito à liberdade religiosa, almejado no período colonial norte-americano, ainda não havia sido reconhecido como um direito fundamental positivado no ordenamento jurídico daquele país, visando à proteção da dignidade humana. Esse foi um processo que ocorreu de forma lenta e gradual ao longo de anos. Como o movimento Flushing Remonstrance contribuiu para o estabelecimento da liberdade religiosa no período colonial é um ponto de investigação na presente reflexão.

\section{SOBRE A COLONIZAÇÃO NA REGIÃO DE NOVA YORK}

A região de Manhattan foi colonizada inicialmente por holandeses. 0 desenvolvimento da colônia foi rápido e, em pouco tempo, aumentou-se sua extensão territorial. Muitos imigrantes afluíram para lá, motivados pela Companhia Holandesa das Índias Ocidentais, "que para incentivar a imigração, concedia vastos domínios a todos que levassem 50 trabalhadores" (MAUROIS, 1946, p. 45). Um traço predominante dessa região - inicialmente sob o domínio holandês e, posteriormente, inglês - era que os que ali chegavam tinham o objetivo de fazer dinheiro. "Tendo sido conquistada em vez de criada, a colônia britânica de Nova York não deveu seu desenvolvimento inicial ao partidarismo inglês. Teve, porém, realmente, uma herança quase antagônica à unidade colonial" (COBEN; RATNER, 1985, p. 41). Possivelmente por esse motivo, ao contrário de outras colônias, não eram feitas exigências religiosas dos que para ali afluiam em busca de trabalho.

Em pouco tempo, desde que a Companhia Holandesa das Índias Ocidentais, sob a liderança do capitão Henry Hudson', descobriu a baía de Nova York acidentalmente, quando procurava por uma rota ocidental para a Ásia, diversas outras expedições foram feitas, despertou-se em muitas outras pessoas grande interesse financeiro na região e o local recebeu tantos imigrantes que, em pouco tempo, ali se falavam cerca de 16 idiomas. Ao passar na região, Hudson registrou que vira grande quantidade de castores (HISTÓRIA..., 2020). A pele desses animais poderia gerar um negócio lucrativo na Europa e isso impulsionou ainda mais o inte-

1 - Henry Hudson (1550-1611): navegador e explorador inglês. Foi contratado por mercadores ingleses e entre os anos de 1608 e 1609 comandou duas expedições nos mares árticos para descobrir uma passagem para a China pelo nordeste, ao norte da Ásia, ou pelo noroeste. Em 1609, renovou a tentativa, dessa vez financiado pela Companhia Holandesa das Índias Orientais, e descobriu o rio que recebeu seu nome, na América do Norte. 
resse na região. Nesse cenário, a cultura comercial da colônia favoreceu uma pluralidade no convivio entre diferentes religiões. A Companhia Holandesa das Índias Ocidentais obteve uma Carta-Régia para explorar a região, adquirindo dos indios a llha de Manhattan.

\begin{abstract}
Em 1625, a Companhia Holandesa das Índias Ocidentais instalou na ilha de Manhattan um entreposto comercial. As pessoas que para ali se mudaram só tinham uma ambição: fazer dinheiro. Por isso, acolheram todos os que os ajudassem a atingir este fim, independentemente de convicções religiosas. Em Nova Amsterdã, nome da cidade criada ao redor do entreposto, não se faziam testes de fé para aceitar um novo morador. Já em 1640, ali se falavam dezesseis línguas diferentes (SILVA, 2009, p. 79-80).
\end{abstract}

Foi nesse processo de crescimento que a região de Flushing se desenvolveu. Estabelecida em 1645 por não conformistas ingleses oriundos da Holanda, a região ainda hoje é conhecida pelo mesmo nome e fica no Condado do Queens, em Nova York. Nesse local, foi vivenciado um dos primeiros movimentos coletivos em prol da liberdade religiosa, protagonizado por trabalhadores imigrantes. Esse movimento revelou que

embora desde o início os holandeses tivessem recebido bem imigrantes de grupos étnicos diversos, os porta-vozes da Igreja Reformada holandesa procuraram seriamente preservar uma aparência de pureza religiosa (COBEN; RATNER, 1985, p. 41).

Judeus recém-chegados do Brasil, que fugiam da cidade de Recife por perseguições religiosas, puderam ali habitar pacificamente. Não Ihes foi permitido abrir uma sinagoga - isso estava totalmente fora de cogitação para o governador da colônia -, mas, de qualquer forma, a cultura na colônia holandesa indicava uma maior tolerância religiosa do que as colônias dos vizinhos ingleses.

Em razão dos objetivos mercantis, as questões religiosas sujeitavam-se a um segundo plano, mas estavam presentes, tanto quanto nas demais colônias. 0 pensamento religioso majoritário era da igreja reformada holandesa e qualquer religião que ameaçasse ocupar seu espaço teria que ser suprimida. A liberdade religiosa, na prática, não existia, exceto uma certa tolerância limitada.

A religião estava no centro das motivações do indivíduo, mesmo na Nova Holanda. A religião foi característica marcante do pensamento dos que migraram para a América do Norte e fator central na formação da nação.

Igualmente não reconhecido na época, mas igualmente importante na formação de um elo básico entre os colonos americanos, foi a similitude de sua visão sobre vários aspectos fundamentais de sua sociedade (COBEN; RATNER, 1985, p. 45). 
A aparente contradição entre um governo autoritário e o anseio por liberdade, bem marcado no pensamento puritano, também esteve presente nas demais colônias.

Outra aparente contradição na Nova Inglaterra dava-se entre esse governo autoritário e a crença na liberdade, que fora um dos elementos principais do próprio movimento em direção à América. E essa contradição acabou gerando resultados políticos da mais alta importância para a comunidade e a futura nação (SILVA, 2009, p. 77).

\title{
O PROTESTO
}

0 protesto conhecido como Flushing Remonstrance ocorreu no dia 27 de dezembro de 1657, em Flushing, em favor de um membro da religião quaker ${ }^{2}$. Membros dessa denominação não eram bem-vistos em vários lugares, inclusive na Inglaterra. Eram conhecidos como uma seita religiosa que havia levado o protestantismo puritano a consequências extremas.

\begin{abstract}
A Sociedade dos Amigos, aos quais foi dado o nome de Quaker porque sua emoção, quando o Sopro Divino se apoderava deles, os fazia tremer, era uma seita religiosa que havia levado o protestantismo puritano às suas consequências extremas. [...] Os Quakers eram pacifistas, adoravam mais um Deus de amor do que um Deus de vingança. [...] Na Inglaterra foram perseguidos e muitos emigraram para as colônias, onde foram enforcados (MAUROIS, 1946, p. 43).
\end{abstract}

Durante o período em que a região ainda era controlada pelos holandeses, Peter Stuyvesant, conhecido por sua grande capacidade de administração, mas também por sua implacável rigidez, foi enviado como governador da colônia holandesa.

Ao longo do vale de Hudson foram erguidas belas residências ornadas de retratos de familia. Os Van Cortlandt, os Van Rensselaer, os Beekmann, e os Schuyler possuiam milhares de acres e a formação desse feudalismo provocava um grande descontentamento entre os colonos menos ricos. A fim de pôr ordem na situação, a Companhia enviou em 1643 um diretor enérgico e interessante, Peter Stuyvesant. Ele tinha uma perna de pau (haviam-no apelidado de Velho Unhas de Prata) e a alma de um ditador. "É possivel", disse ele ao chegar,

\footnotetext{
2 - Quaker é o nome dado a vários grupos religiosos com origem no protestantismo inglês do século XVII. Quakerismo, Sociedade Religiosa dos Amigos ou simplesmente Sociedade dos Amigos também são outros nomes dados a esses grupos. Eles são conhecidos pela defesa do pacifismo e da simplicidade, rejeitando qualquer organização clerical, para viver no recolhimento, na pureza moral e na prática ativa do pacifismo, da solidariedade e da filantropia.
} 
"que durante minha administração haja pessoas inclinadas a apelar de minhas decisões aos Estados Gerais. Se isso suceder, eu encurtarei palmo e meio de seu tamanho e mandarei os pedaços para a Holanda, onde eles se quiserem poderão apelar (MAUROIS, 1946, p. 45).

O governador Stuyvesant não tolerava a prática de outras religiões, além da adotada pela Igreja Reformada Holandesa. 0 ministro inglês, Robert Hodgson, havia se tornado um influente ministro quaker e sua religião era considerada abominável para os líderes da colônia. Possivelmente ele viera da Inglaterra para fugir de opressão religiosa, como muitos outros. Stuyvesant mandou espancar brutalmente o jovem Hodgson, de 23 anos, por motivos religiosos, lançando-o posteriormente à prisão. "E então ele emitiu uma ordenança severa, punível com multa e prisão, contra qualquer um considerado culpado de abrigar quakers" (JACKSON, 2017, tradução nossa). A crueldade aplicada na tortura pública de Hodgson foi tão brutal, que gerou um protesto dos moradores de Flushing. Edward Hart, secretário da cidade, rapidamente reuniu cidadãos locais para a emissão de uma petição formal, assinada por cerca de 28 homens influentes, exigindo liberdade religiosa. A petição citava a "Carta da Cidade de Flushing de 1645, que prometia liberdade de consciência" (JACKSON, 2017, tradução nossa). No entanto, os líderes do movimento foram presos e os demais signatários foram obrigados a excluir seus nomes do documento para evitar a prisão.

Embora o episódio, conhecido como "Flushing Remonstrance" tivesse acabado mal (o líder dos que protestaram, Edward Hart, foi preso, e os demais foram obrigados a retirar o nome do documento sob pena de também serem aprisionados), ele representou um momento histórico para a liberdade de consciência e da religião no continente (SILVA, 2009, p. 80).

Na mentalidade dos moradores de Flushing, outras colônias lutaram de maneira mais expressiva do que eles para o estabelecimento da liberdade religiosa na América. No entanto, para eles, a demissão de funcionários da cidade, as ameaças de banimento, as multas e a prisão de alguns dos signatários do documento não foram suficientes para suprimir o espírito de tolerância, que não era comum na época (TREBOR, 1953). Para eles, esse movimento contribuiu para a liberdade religiosa da colônia e da nação.

\section{Resultados do movimento}

0 protesto de Flushing foi um dos movimentos que abriram o caminho para o estabelecimento da liberdade religiosa na colônia e na mentalidade dos imigrantes. Vale ressaltar que a busca pela liberdade estava presente no fenômeno migratório entre Europa e América do Norte, ocorrido no século XVII. Semelhantemente ao ser humano, que, no processo de crescimento, deseja autonomia, o processo de transformação rumo à liberdade religio- 
sa foi bem estabelecido após décadas de lutas, tornando-se um traço característico dos Estados Unidos.

Em 1645, o governador William Katt, da província holandesa, havia prometido, na carta aos seus fundadores, o direito de ter e gozar de liberdade de consciência (TREBOR, 1953). Esse documento foi citado na petição endereçada ao governador Stuyvesant em 1657. Como autoridade da colônia, o governador decidiu desprezar o documento legal e agiu conforme seus costumes, revelando a velha mentalidade europeia. "A emergência de noções de individualidade, no sentido moderno, pode ser relacionada ao colapso da ordem social, econômica e religiosa medieval" (WILLIAMS apud HALL, 2006, p. 28). Nesse aspecto, o movimento de Flushing realçou a nova mentalidade que estava surgindo naquele período.

A cultura predominante era prisão, tortura, violência e morte aos desobedientes. Os peticionários a nada desobedeceram, apenas pleitearam ao representante do poder público que a lei de liberdade de consciência, determinada na Carta-Régia da Colônia, fosse respeitada, sob a justificativa de que eles não poderiam ferir suas próprias consciências, agindo com violência gratuita contra os quakers, porque tinham obrigação de obedecer à lei de Deus e dos homens, fazendo o bem a todos e o mal a ninguém. A lei de Stuyvesant determinava que qualquer um que abrigasse um quaker deveria ser multado e preso. Comparato, falando sobre o século XVII, diz que todo o período, e não apenas a fase de transição para o século seguinte, foi "um tempo de crise de consciência europeia, uma época de profundo questionamento das certezas tradicionais" (COMPARATO, 2015, p. 47).

Nesse sentido, vemos que os signatários da petição refletem o momento histórico em que viveram, pois decidiram questionar seu governante. Exceto isso, nada fizeram para merecer prisão, multa, perda de seus empregos e ameaça de banimento. 0 poder absoluto estava sendo questionado pela nova consciência que estava começando a florescer à época.

0 inglês John Bowne, um conservador que havia chegado a Massachusetts em 1627, protagonizou uma mudança importante quanto à liberdade religiosa. Ele se mudou com sua família para Flushing em 1651. Ao finalizar a construção de sua casa, em 1661, Bowne convidou os quakers para lá adorar e em pouco tempo tornou-se um deles. Stuyvesant, ao descobrir que em sua residência eram realizados cultos da denominação que ele chamava de seita abominável, emitiu em agosto de 1662 um mandado de prisão contra Bowne, que também foi multado e recebeu um aviso severo para se abster de qualquer reunião quaker, "sob pena de ter o valor da multa dobrado e de ser banido da colônia" (TREBOR, 1953, p. 6). Bowne recusou-se a pagar a multa e a renunciar ao seu direito de liberdade. Após ser preso em uma masmorra solitária, com escasso pão e água, Stuyvesant decidiu enviá-lo à Holanda para resolução do caso. Durante seu julgamento, decidiu fazer um pedido de tolerância e liberdade de consciência e foi absolvido. Como resultado do seu pedido, a Câmara de Amsterdã, da Companhia Holandesa das Índias Ocidentais, declarou que a consciência do homem devia permanecer livre e sem restrições. Para os moradores de Flushing, o caso de Bowne foi 
fruto do movimento de 1657 e, somado a outros, contribuiu para a construção dos conceitos de liberdade, posteriormente descritos na Declaração de Independência em 1776 (TREBOR, 1953). Após esse episódio, foi permitido na colônia que todos tivessem sua própria crença, porém, com diversos outros relatos de conflitos dessa ordem.

0 protesto de Flushing ficou registrado na história como um movimento que abriu o caminho para o afrouxamento das rígidas regras de intolerância. A violência com que foi aplicada a tortura ao jovem inglês Robert Hodgson impressionou a todos, causando uma aversão ao governador Stuyvesant, o que, certamente, aumentou com o caso de Bowne. Os quakers sofriam grande antipatia em grande parte das colônias e foram duramente perseguidos. No entanto, para Comparato, esse grupo religioso muito contribuiu para a fundação de uma sociedade igualitária, por serem "resolutamente antimonarquistas que reivindicavam a posse em comum das terras de lavoura e recusavam-se a tirar o chapéu diante das autoridades" (COMPARATO, 2015, p. 96). Por esses motivos, não é difícil compreender por que esse grupo religioso foi um dos mais perseguidos durante o período colonial. De acordo com Maurois, a coroa não daria uma concessão a esse grupo, considerado, na época, uma seita detestável. No entanto, em 1681, William Penn ${ }^{3}$ obteve do rei uma carta pessoal que the conferia uma grande propriedade, que ele chamou de Pensilvânia. Ali os quakers puderam habitar pacificamente (MAUROIS, 1946).

0 tratamento dado ao jovem inglês Hodgson surgiu no cenário histórico como uma possibilidade de motivação extra, pela qual os britânicos invadiram o território dominado pelos holandeses e assumiram o controle sem encontrar resistência, já que os ingleses não estavam confortáveis com uma colônia holandesa no meio do seu domínio. No entanto, essa afirmação carece de pesquisa mais aprofundada e não é objeto desta pesquisa. Poderia o elemento da perseguição religiosa aos ingleses ter sido parte da motivação para que Carlos II invadisse a região de domínio holandês? É possivel que Flushing Remonstrance tenha ecoado até a coroa britânica, de forma a motivar as suas naus e a alterar a configuração política da região?

\section{Breve análise sobre o movimento}

Muitos movimentos importantes no pensamento e na cultura ocidentais contribuíram para a emergência desta nova concepção: a Reforma e o Protestantismo, que libertaram a consciência individual das instituições religiosas da Igreja e a expuseram diretamente aos olhos de Deus [...] (HALL, 2006, p. 26).

3 - William Penn (1644-1718): inglês e fundador da provincia de Pensilvânia, uma colônia inglesa que posteriormente se tornou um estado americano. Os princípios liberais que ele implementou na colônia serviram como uma fonte de inspiração para a Constituição dos Estados Unidos da América. 
A Reforma Protestante abriu o caminho para a autonomia individual perante o Estado e a Igreja. Quanto a essas transformações, há um consenso entre os historiadores sobre 0 modo como esse movimento foi decisivo na construção da mentalidade ocidental e no pensamento do homem moderno. É muito difícil compreender o que se denomina Era Moderna sem a reforma religiosa. Ela trouxe liberdade de consciência ao cidadão e limitou as autoridades políticas e religiosas. A América do Norte recebeu a influência desse movimento religioso por meio de seus imigrantes, que baseavam os princípios norteadores de suas ações na religião. A petição do movimento de Flushing corrobora essa ideia. Foi escrita, como muitos outros documentos americanos, com base na religião de seus autores, sob o princípio do amor ao próximo. A petição que constituiu importante documento na história da liberdade religiosa da América do Norte demonstrou um traço relevante que se tornou parte da identidade do pensamento americano, como citado por Coben e Ratner (1985, p. 47): "o melhor exemplo de unidade fundamental na América do século XVII em fase de ostensiva fragmentação talvez tenha estado no domínio da religião. A maioria dos primeiros imigrantes era protestante".

A petição também é considerada precursora da Constituição e da Carta de Direitos dos Estados Unidos. Esse documento "representou um momento histórico para a liberdade de consciência e da religião no continente", porque seus peticionários "agiram em favor de um princípio, não em benefício próprio" (SILVA, 2009, p. 80).

Usaram os meios legais para expressar a sua manifestação e expuseram diante da autoridade competente os motivos do protesto. 0 direito de ter e gozar de liberdade de consciência estava previsto na patente concedida à colônia e os signatários da petição basearam seu pedido nesse direito. Ou seja, eles não obedeceriam à imposição do governador Stuyvesant, agindo com violência contra os quakers e contra as suas próprias consciências, pois reconheciam que essas estavam sob a influência da lei de Deus. Não desejavam, com isso, opor-se ao Estado ou à Igreja, mas fazer o contrário seria obrigá-los a agir contra a própria consciência. 0 documento também revela que eles viam os quakers como seus iguais na fé, a despeito de suas diferenças doutrinárias, e que se recusavam a usar a violência por motivos religiosos. A objeção de Flushing pretendia a não assimilação de leis que violassem a liberdade de consciência e, consequentemente, a dignidade humana.

A imediata resistência tão bem formulada na petição manifestamente contrária ao ato do governo local pode representar o indício da influência do famoso reformador Roger Williams, que havia chegado à América do Norte em 1631. Após ser formalmente julgado e banido de Massachusetts, ele fundou Rhode Island, a primeira colônia americana, criada sob a concepção da separação Igreja-Estado e onde seria tolerada a liberdade religiosa. Williams defendia a liberdade de consciência como um direito inato e inalienável do ser humano. Baseava suas teses no direito à liberdade de consciência e religiosa e na igualdade de todos perante a lei. Para ele, a Igreja era baseada no amor de Deus, enquanto o Estado era baseado 
na espada. Ele acreditava que a espada civil poderia fazer uma nação de hipócritas e anticristãos, mas não um cristão (WILLIAMS, 1848). Williams acreditava "que a vontade da maioria das pessoas - expressa por meio de instituições laicas - deveria constituir a base da administração pública" (SILVA, 2009, p. 79). Ele advogava suas ideias em sermões, livros e panfletos. Seus debates sobre liberdade religiosa tornaram-se rapidamente conhecidos.

Edward Hart, o escrivão da petição, pode ter tido contato com as ideias de Williams, pois há registros de que ele poderia ter sido um dos primeiros colonos de Rhode Island. 0 inglês John Bowne, que, após ser perseguido pelo governador Stuyvesant, adquiriu durante seu julgamento na Holanda a garantia da liberdade religiosa para a colônia, pode ter estado com Williams. Antes de mudar para Flushing, Bowne havia morado na Colônia de Massachusetts, onde Williams também morou, causando grande polêmica entre os puritanos. Certamente, o exemplo de Williams e as sementes de suas ideias lançadas sobre o funcionamento do Estado diante de questões religiosas conquistaram discípulos.

0 historiador Kenneth T. Jackson ${ }^{4}$, ao escrever, 350 anos depois, sobre o protesto de Flushing, no famoso jornal americano The New York Times, listou quatro motivos que, em sua visão, fizeram o movimento notável. 0 primeiro deles foi que o protesto articulou um direito fundamental, considerado básico para a liberdade americana. 0 segundo, que os peticionários que assinaram o documento não sussurraram sobre sua oposição e não protestaram em silêncio.

De fato, para protagonizar o primeiro movimento em favor da liberdade religiosa, eles assinaram um documento e enviaram-no a um dos funcionários mais poderosos da colônia, um homem conhecido por ser capaz de enviar de volta à Holanda, aos pedaços, qualquer um que o desafiasse. "Esses homens de diversas opiniões sobre religião corajosamente resistiram a todas as tentativas de que este direito fosse desrespeitado, e para que naquela comunidade fossem aceitas pessoas de todas as religiões" (TREBOR, 1953, p. 6, tradução nossa).

0 terceiro ponto é que nenhum dos signatários da petição era quaker. Eles defenderam o direito à liberdade religiosa em razão de um princípio em que acreditavam, mas não diretamente em benefício próprio. Como resultado, foram perseguidos e alguns, presos - dentre eles, dois magistrados que assinaram o documento, o funcionário que o entregou e o secretário Edward Hart.

Em quarto lugar, Jackson realça que a linguagem usada na petição era tão bonita quanto os sentimentos ali expressos:

Se alguma dessas pessoas vier a nós com amor, não podemos, em consciência, impor mãos violentas sobre elas, mas dar-Ihes saida e regresso livre à nossa cidade. Pois somos obriga-

4 - Kenneth Terry Jackson é professor de História na Columbia University e editor-chefe da The Encyclopedia of New York City. 
dos pela lei de Deus e do homem a fazer o bem a todos os homens e o mal a ninguém (JACKSON, 2017, tradução nossa).

Para ele, a tolerância atribuída aos assentamentos holandeses foi consequência da liberdade de consciência consagrada na Holanda em 1579, e porque o motivo de a Companhia Holandesa das Índias Ocidentais ter estabelecido um posto comercial no extremo sul de Manhattan era exploração econômica, e não salvação de almas. Por isso, um esforço foi feito para que todos fossem bem-vindos. No entanto, Jackson admite que, mesmo na Nova Amsterdã, a tolerância religiosa tinha seus limites, especialmente quando se tratava dos quakers. Para ele, foi esse episódio que abriu a porta para a tolerância religiosa se tornar lei na colônia, a pedido de Bowne, em 1662. Em sua visão, o nascimento da liberdade religiosa no continente está ligado à petição de Flushing.

\section{CONCLUSÃO}

Flushing Remonstrance foi um movimento que não produziu, naquele episódio, um resultado imediato. Contudo, esse movimento fortaleceu o pensamento da liberdade de consciência como valor máximo a ser perseguido e contribuiu para a implantação da cultura da liberdade religiosa na colônia holandesa e, posteriormente, na nova nação.

0 movimento implicou resistência às regras religiosas impostas pelo Estado. Seus signatários deixaram evidente que as autoridades civil ou religiosa não deveriam ter a competência de legislar sobre matéria de consciência. Isso seria violar um direito inato do ser humano. Esse modelo foi rejeitado e demonstrou-se inadequado, porque, em sua mentalidade, 0 poder público não poderia cercear a prática da religião que contrariasse a religião oficial, tampouco poderia obrigar seus cidadãos a unirem-se ao Estado com o objetivo de perseguirem violentamente as pessoas de denominação diferente, única e exclusivamente por não se conformarem à fé majoritária. Além disso, a escolha da religião não caberia ao poder público. Por ser uma escolha pessoal, acreditavam que essa dependia da liberdade de consciência, no uso do livre-arbitrio, dado a cada ser humano, por Seu Criador.

0 processo embrionário da democracia moderna estava em plena atividade no período colonial e o movimento de Flushing Remonstrance fez parte desse processo, que foi concretizado no século XVIII pelos pais fundadores. "A soberania popular acha-se intimamente unida ao reconhecimento de 'direitos inalienáveis' de todos os homens, 'entre os quais a vida, a liberdade e a busca da felicidade'" (COMPARATO, 2015, p. 102). 


\section{Flushing Remonstrance: the background of religious freedom in North America}

Abstract: This reflection examines the origins of religious freedom in North America. Starting from the Flushing Remonstrance movement, which took place in the 17th century, considered one of the pioneers in the field of protest in defense of tolerance and religious freedom, we sought to identify the main characteristics of that movement that served as the foundation for the North American society to be one of the first nations to consider the issue in their constitution and Charter of Rights.

Keywords: Religion. Freedom. Tolerance. Protest. North America.

\section{REFERÊNCIAS}

COBEN, S.; RATNER, N. O desenvolvimento da cultura norte-americana. Rio de Janeiro: Anima, 1985.

COMPARATO, F. K. A afirmação histórica dos direitos humanos. 11. ed. São Paulo: Saraiva, 2015.

CRUNDEN, R. M. Uma breve história da cultura americana. Rio de Janeiro: Nórdica, 1994.

HALL, S. A identidade na pós-modernidade. Rio de Janeiro: DPEtA, 2006.

HISTÓRIA DA CIDADE DE NOVA IORQUE. In: Wikipédia: a enciclopédia livre. Disponivel em: https://pt.wikipedia.org/wiki/Hist\%C3\%B3ria_da_cidade_de_Nova_lorque. Acesso em: 20 jul. 2020.

JACKSON, K. T. A colony with a conscience. The New York Times, 2017. Disponivel em: https:// www.nytimes.com/2007/12/27/opinion/27jackson.html. Acesso em: 20 jul. 2020.

MAUROIS, A. A história dos Estados Unidos. São Paulo: Companhia Editora Nacional, 1946.

SILVA, C. E. L. da. Uma nação com alma de igreja: religiosidade e políticas públicas nos Estados Unidos. São Paulo: Paz e Terra, 2009.

TREBOR, H. Bowne House: a shrine to religious freedom. New York: Bowne House Historical Society, 1953.

WILLIAMS, R. The bloudy tenent of persecution: for cause of conscience discussed. London: The Hanserd Knollys Society, 1848. 